AperTO - Archivio Istituzionale Open Access dell'Università di Torino

\title{
A one-pot ultrasound-assisted water extraction/cyclodextrin encapsulation of resveratrol from Polygonum cuspidatum.
}

\section{This is the author's manuscript}

Original Citation:

Availability:

This version is available http://hdl.handle.net/2318/92546

since 2016-07-20T13:09:54Z

Terms of use:

Open Access

Anyone can freely access the full text of works made available as "Open Access". Works made available under a Creative Commons license can be used according to the terms and conditions of said license. Use of all other works requires consent of the right holder (author or publisher) if not exempted from copyright protection by the applicable law. 


\section{(3) \\ UNIVERSITÀ DEGLI STUDI DI TORINO}

This Accepted Author Manuscript (AAM) is copyrighted and published by Elsevier. It is posted here by agreement between Elsevier and the University of Turin. Changes resulting from the publishing process - such as editing, corrections, structural formatting, and other quality control mechanisms - may not be reflected in this version of the text. The definitive version of the text was subsequently published in [Food Chemistry, volume number 130, issue number 3, 2012, DOI: 10.1016/j.foodchem.2011.07.038].

You may download, copy and otherwise use the AAM for non-commercial purposes provided that your license is limited by the following restrictions:

(1) You may use this AAM for non-commercial purposes only under the terms of the CC-BY-NC-ND license.

(2) The integrity of the work and identification of the author, copyright owner, and publisher must be preserved in any copy.

(3) You must attribute this AAM in the following format: Creative Commons BY-NC-ND license (http://creativecommons.org/licenses/by-nc-nd/4.0/deed.en), [DOI: 10.1016/j.foodchem.2011.07.038] 


\title{
A one-pot ultrasound-assisted water extraction/cyclodextrin encapsulation of resveratol from Polygonum cuspidatum
}

\author{
Stefano Mantegna, Arianna Binello, Luisa Boffa, Marta Giorgis, Clara Cena, Giancarlo Cravotto* \\ Dipartimento di Scienza e Tecnologia del Farmaco, Università di Torino, Via P. Giuria 9, 10125 \\ Torino, Italy. \\ *Author to whom correspondence should be addressed \\ (telephone +39 011.6707684; fax +39.011.6707687; e-mail: giancarlo.cravotto@ unito.it)
}

\begin{abstract}
The ultrasound-assisted extraction (UAE) of resveratrol and other polyphenols from Polygonum cuspidatum has been carried out with the aim to developing an efficient and eco-friendly extraction process. The finely milled roots were sonicated (titanium horn, $19.5 \mathrm{kHz}$ ) in methanol, in different cyclodextrin water solutions [ $\beta$-cyclodextrin $(\beta-\mathrm{CD})$ or hydroxypropyl $\beta$-CD $(\mathrm{HP} \beta-\mathrm{CD})]$ and also in pure water. UAE dramatically increased the yields and cut down extraction times compared to conventional extraction under stirring. Outstanding results have been achieved with the $\beta-C D$ solution $(1.5 \% \mathrm{w} / \mathrm{w})$; in fact HPLC analysis showed that the selective inclusion properties of CDs toward phenolic stilbenes gave a much cleaner analytical extract profile. This green method gave $7.51 \mathrm{mg}$ of total resveratrol (free + cleaved polydatin glucoside) per gram of dry plant. Thanks to polyphenol encapsulation within CDs, this extract showed excellent water dispersibility, higher stability and an antioxidant power which is comparable to that of the MeOH extract (DPPH, $\mathrm{ORAC}_{\mathrm{FL}}$ ). These important features should pave the road for its application in food supplements or phytochemical preparations.
\end{abstract}

Keywords: Resveratrol, polyphenols, Polygonum cuspidatum, ultrasound-assisted extraction, cyclodextrins

\section{Introduction}

Resveratrol and polydatin (piceid) are phenolic stilbenes synthesized by several plants as a defence response to situations of stress such as microbial infection, UV irradiation or mechanical damage (Okuda \& Yokotsuka, 1996; Pezet, Perret, Jean-Denis, Tabacchi, Gindro \& Viret, 2003). These molecules were found to be the major polyphenols present in the root of Polygonum cuspidatum. Their content is much higher in this plant than in grape berries. P. cuspidatum (Polygonaceae) is a perennial plant widely distributed in China, Japan and Korea and also found growing throughout North America. The dried roots of this plant were traditionally used in China and Japan as herbal folk remedies for the treatment of atherosclerosis, cough, asthma, hypertension and even cancer (Vastano, Chen, Zhu, Ho, Zhou \& Rosen, 2000). Resveratrol and polydatin are widely used in medicine and health products on account of their important biological activities which include anti- 
inflammatory, anticancer and cardioprotective action (Bertelli et al., 1999; Li, Chen, Huang, Lee \& $\mathrm{Su}, 2000)$. The antioxidant properties of resveratrol and related compounds are certainly involved in these molecules' mechanism of action and because of the wide range of possible health benefits these polyphenols present, a huge effort has been made towards the development of isolation, purification and quantification methodologies. Conventional methods entail extraction by heating under reflux with ethanol, followed by filtration, concentration and purification. This procedure is time consuming and requires a large amount of solvent (Liu, Tang, Zhang, Bi, Wang \& Zhao, 2007; Xiang, Zhou, Lei \& Chen, 2005). Other authors have experimented with molecular imprinted polymers for the selective extraction and purification of resveratrol and piceid from the same plant (Zhuang, Dong, Ma \& Zhang, 2008). Supercritical fluid extraction (SFE), which primarily uses $\mathrm{CO}_{2}$ as its extraction medium, has been widely used for the extraction of non polar substances such as oils from natural plants and recent literature has shown that it can also be used for the extraction of resveratrol from $P$. cuspidatum when either ethanol or acetonitrile is added as a modifier ( $\mathrm{Yu}$, Shu \& Zhao, 2005; Benova, Adam, Pavlikova \& Fischer, 2010). Microwave-assisted extraction (MAE) has also been reported (Li, Li \& Zhang, 2003; Wang, Dong \& Xiu, 2008). The authors presented a series of advantages that their integrated method showed: short extraction time, reduced amount of solvent and direct concentration.

To the best of our knowledge ultrasound-assisted extraction (UAE) has never be applied to the extraction of this important natural source of resveratrol. It is well known that UAE technology can have a significant effect on the rate of various processes in the food chemistry (Chemat, e-Huma \& Khan, 2011) and enhance the extraction of natural products from plant material, such as polyphenols, anthocyanins, flavonoids (Mason et al., 2011; Cravotto \& Cintas, 2007). In a recent paper we have compared UAE, MAE and other extraction techniques to obtain phenolics from Vitis vinifera waste (Casazza, Aliakbarian, Mantegna, Cravotto \& Perego, 2010). The shear forces created by the implosion of cavitation bubbles which are in turn created by ultrasonic waves disrupt plant tissues and facilitate extraction at room temperature. The easy scaling up of UAE, the safety aspects, the low energy consumption and the moderate investment required make this technique very attractive for industrial application. Sonication has been used to extract resveratrol and others phenolics from peanuts (Chukwumah, Walker, Verghese \& Ogutu, 2009).

The conventional methods used to purify stilbene compounds from $P$. cuspidatum utilized a liquidliquid partition together with silica gel column chromatography which required a large amount of organic solvents (Sun \& Zhang, 2003). High-speed counter-current chromatography purification has recently been reported (Fan, Marston, Hay \& Hostettmann, 2009), as has a two-step purification with macroporous resin adsorption and reverse-phase liquid chromatography (Zhang et al., 2009). All these protocols allow the recovery of resveratrol-enriched extracts although they are lacking in sustainability and are far from what would be expected by process intensification strategies.

Cyclodextrins (CDs) are well known for their ability to form inclusion complexes between bioactive compounds and their peculiar hydrophobic cavity (Cravotto, Binello, Baranelli, Carraro \& Trotta, 2006) This increases the solubility, stability and bioavailability of the guest compound and therefore it is no surprise that their use in food and pharmaceutical industry is becoming ever more common (Szente \& Szejtli, 2004). The relatively high hydrophobicity of resveratrol and its sensitivity to external agents such as air, light and oxidative enzymes constitutes a serious problem for its formulation, manipulation and bioavailability. An answer to these limitations is the inclusion of resveratrol in CD derivatives as has been suggested by several authors in a series of formulations (Lopez-Nicolas, Rodriguez-Bonilla \& Garcia-Carmona, 2009; Lucas-Abellán, Fortea, Lopez- 
Nicolas \& Núñez-Delicado, 2007; Lu, Chen, Liu, Hu, Cheng, \& Zou, 2008; Lu, Cheng, Hu, Zhang, \& Zou, 2009).

In this piece of work we combine the UAE of $P$. cuspidatum roots and the CDs encapsulation of resveratrol and polydatin in one step. This is done using $\beta-\mathrm{CD}$ or $\mathrm{HP} \beta-\mathrm{CD}(1.5 \% \mathrm{w} / \mathrm{w})$ in water. The strong favourable effect of power ultrasound on the extraction process has been demonstrated both in methanol and in CDs solutions.

\section{Material and methods}

\subsection{Instrumentation}

HPLC analyses were performed with a Waters 1525 Binary HPLC pump equipped with 2998 PDA and 2424 ELS detectors. UAE was performed using a high-power probe system with an immersion titanium horn, frequency $19.5 \mathrm{kHz}$ in a power range of 50-100W. The extraction temperature was kept constant at $20^{\circ} \mathrm{C}$ by means of a thermostatted cooling bath.

UV analyses for DPPH tests were performed on Cary 50Bio spectrophotometer (Varian).

\subsection{Chemicals and reagents}

Analytical-grade methanol (Carlo-Erba Reagenti) was used for the preparation of samples and standards solutions of resveratrol and polydatin. The resveratrol $(99 \%)$ and polydatin $(>95 \%)$ reference samples were purchased from Sigma-Aldrich. $\beta-C D$ and HP $\beta-C D$ were kindly provided by Wacher Chemie (Germany). HPLC-grade acetonitrile (Carlo-Erba Reagenti), Milli-Q water and formic acid (Sigma-Aldrich) were used as HPLC mobile phase.

\subsection{Materials and sample preparation}

For the calibration curve of resveratrol and polydatin, standard solutions at 1, 80, 160, 240, 320 and $480 \mu \mathrm{g} / \mathrm{ml}$ concentrations were prepared in methanol and a $30 \mu \mathrm{l}$ amount of each was injected for HPLC analysis. Small portions (25 g) of $P$. cuspidatum roots were pulverized in a plant blender (Blendor, Warig Commercial) at a size range of 300-400 $\mu \mathrm{m}$ before extraction.

\subsection{Extraction procedure}

Finely milled roots $(2 \mathrm{~g})$ and solvent $(50 / 100 \mathrm{ml}$ of methanol or CD water solutions, see Table 1$)$ were introduced into a three-necked pear-shaped $250 \mathrm{ml}$ flask and the mixture was stirred at room temperature for $3 \mathrm{~h}$ or treated under US irradiation for $1 \mathrm{~h}$ at $20^{\circ} \mathrm{C}$. US extraction started with a preliminary hard treatment of $5 \mathrm{~min}$ at $100 \mathrm{~W}$ for an effective cell wall disruption followed by a second step of $55 \mathrm{~min}$ at $50 \mathrm{~W}$ for an efficient mass transfer. Typical ratio solvent/plant was 50 $\mathrm{ml} / \mathrm{g}$. The suspension was centrifuged at $3500 \mathrm{rpm}$ to obtain a clear orange-brown solution and the precipitate was washed with $10 \mathrm{ml}$ of fresh solvent (methanol or water). The methanol extracts were concentrated under vacuum and then transferred to a $100 \mathrm{ml}$ volumetric flask (final volume of 100.0 $\mathrm{ml}$ ). $30 \mu \mathrm{l}$ aliquots were used for HPLC analysis. The $\beta$-CD aqueous extracts were freeze dried overnight and $100 \mathrm{ml}$ of methanol was added to precipitate $\beta-\mathrm{CD}$ and keep the phenolic compounds from the $\beta$-CD complex in solution. The white precipitate formed was washed with methanol (50 $\mathrm{ml}$ ). The two methanol aliquots were collected, concentrated under vacuum and then transferred to a $100 \mathrm{ml}$ volumetric flask (final volume of $100.0 \mathrm{ml}$ ). The same HPLC analysis followed.

\subsection{HPLC analyses}


The column used for analyses was a Luna C18 (5 $\mu \mathrm{m}, 250 \mathrm{~mm}$ x $4.6 \mathrm{~mm}$; Phenomenex) and 0.4\% formic acid in Milli-Q water (A) and acetonitrile (B) were used as the mobile phase. The gradient program started from $15 \% \mathrm{~B}$ up to $20 \% \mathrm{~B}$ over the $0-20$ min period, from 20 to $40 \%$ B over $20-40$ min, from 40 to $100 \%$ B over $40-60$ min followed by a $100 \%$ B step over $60-65$ min.

\subsection{Determination of reactivity with DPPH•}

The radical scavenging properties of the extracts were determined through reactivity with the stable 2,2-diphenyl-1-picrylhydrazyl radical (DPPH) (Bondet, Brand-Williams \& Berset, 1997). Ethanol solutions of the extracts $(\mu \mathrm{g} / \mathrm{ml})$ were prepared at different concentrations and rapidly mixed with an ethanol solution of $\mathrm{DPPH} \bullet$ (final volume $=3 \mathrm{ml}$, final $\mathrm{DPPH} \bullet$ concentration $=60 \mu \mathrm{M}$ ). The absorbance decay of DPPH• solutions after the addition of the extracts was followed for $30 \mathrm{~min}$. In parallel, a blank solution of DPPH• was screened to estimate DPPH• decomposition during the measurement time. Initial and final $\mathrm{DPPH} \bullet$ concentrations were exactly determined by interpolating radical absorbance values at $\mathrm{t}=0$ and at $\mathrm{t}=30 \mathrm{~min}$ with a DPPH $\bullet$ standard curve performed in the concentration range $10-90 \mu \mathrm{M}$. Percentages of residual DPPH $\bullet$ concentration at $30 \mathrm{~min}$ were calculated and correlated $v s$ extract scavenger concentrations, giving an exponential decay curve which was analyzed by non linear regression, to obtain $\mathrm{EC}_{50}$ values.

\subsection{ORAC Assay}

The ORAC test was performed using a Perkin-Elmer 2030 Multilabel Reader with 96-well black plates. $75 \mathrm{mM}$ potassium phosphate buffer $(\mathrm{pH}$ 7.4) was used as a blank and different Trolox solutions, ranging from 0.25 to $6 \mu \mathrm{m}$, were used as standards (Ou, Hampsch-Woodill \& Prior, 2001). The sample solutions were prepared by dissolving the extracts in an ethanol/buffer mixture $(1 / 1 \mathrm{v} / \mathrm{v})$ and diluting them with phosphate buffer. To start the incubation, aliquots of fluorescein (3',6'-dihydroxyspiro[isobenzofuran-1[3H],9' $[9 H]$-xanthen]-3-one) solution (150 $\mu$ l of a $48 \mathrm{nM}$ solution in potassium phosphate buffer) were dispensed into all wells first this was followed by 20 $\mu l$ of either buffer, standard or sample solutions added (all in duplicate). The plate was covered and incubated in the preheated $\left(37^{\circ} \mathrm{C}\right)$ microplate reader for $10 \mathrm{~min}$ which included $3 \mathrm{~min}$ shaking. 30 $\mu \mathrm{l}$ of AAPH (2,2'-azobis(2-amidinopropane) dihydrochloride) solution (133 $\mathrm{mM}$ in phosphate buffer) were added and the reaction started when the plate was inserted into the reader at $37^{\circ} \mathrm{C}$. All fluorescence measurements were expressed relative to the initial reading of the fluorescence signal and were repeated every minute for $35 \mathrm{~min}$ at the emission wavelength of $535 \mathrm{~nm}$ with excitation at $485 \mathrm{~nm}$. The net area under the curve (AUC) was calculated by subtracting the AUC of the blank from the AUC of either the standard or of the sample. The Trolox equivalent molar concentrations were calculated using a linear regression equation between Trolox concentration and the net AUC. To compare the antioxidant activity of the extracts we decided to calculate the relative ORAC values as Trolox micromoles present in $1 \mathrm{~g}$ of dried extract.

\section{Results and Discussion}

Conventional extraction processes for natural antioxidants such as polyphenols are quite laborious, time-consuming, involve large amounts of solvents and may ultimately cause some degradation of the target molecules. Great improvements in the process intensification of the extraction of resveratrol and polydatin from $P$. cuspidatum can be achieved with UAE, and efficient sonication can cut down the extraction time and increase the yields. Table 1 reports the experimental 
conditions and the yields of resveratrol and polydatin which are calculated by molecular weight ratio. In all cases the extraction temperature was kept constant at $20^{\circ} \mathrm{C}$ by means of a thermostatted cooling bath.

\section{Table 1.}

Chromatograms a and $\mathbf{b}$ (Fig. 1) show the HPLC profiles of the $\beta$-CD sol. extract and the methanol extract respectively. The first peak corresponds to polydatin (retention time $19 \mathrm{~min}$ ) and is followed by the free resveratrol peak (34 $\mathrm{min}$ ). The CD selective inclusion property toward phenolic stilbenes caused the differences between the two chromatograms, the profile of the $\beta$-CD sol. extract (a) is much cleaner.

\section{Figure 1}

The optimization and validation of HPLC methods for the quantification of resveratrol and other polyphenols in P. cuspidatum has been the object of previous studies (Qian, Leung, Lu \& Leung, 2008). Comparing these extracts, we observed that $\beta-C D$ sol. gave a higher amount of free resveratrol (2.35 vs $2.15 \mathrm{mg} / \mathrm{g}$ ) and less polydatin $(9.64$ vs $11.84 \mathrm{mg} / \mathrm{g})$. The sugar portion in polydatin probably reduces its affinity to the $C D$ and favours the in-out equilibrium. The influence of sonication was more evident in the extraction with $\beta-\mathrm{CD}$ sol. than for methanol. UAE showed an increase in total resveratrol content in $\beta-C D$ sol. extract over plain stirring of $34 \%$, while this increase was halved in the methanol extract (17\%). A little less resveratrol was recovered when the plant/solvent ratio was decreased from 1:50 to $1: 25$ (1.78 vs $2.35 \mathrm{mg} / \mathrm{g})$. The same was found to be true for polydatin $(7.51$ vs $9.64 \mathrm{mg} / \mathrm{g})$. Finally the extract obtained using $25 \mathrm{ml}$ of $3 \% \mathrm{HP} \beta-\mathrm{CD}$ water solution per $\mathrm{g}$ of plant under UAE did not achieve the yields of the $\beta-\mathrm{CD}(0.85$ and $4.98 \mathrm{mg} / \mathrm{g}$ for resveratrol and polydatin, respectively). Two marvellous and totally distinct colours were observed: yellow for the extract with $\beta$-CD and intense red for HP $\beta$-CD (Fig. 2).

As described in the literature (Lopez-Nicolas, Rodriguez-Bonilla \& Garcia-Carmona, 2009, and references therein), the inclusion complex between $\beta-C D$ and resveratrol increases its stability in solution, preserving it from air and light degradation (cis-trans conversion). Moreover $\beta$-CD decreases the aggregation of resveratrol molecules, increases the bioavailability and the antioxidant activity.

\section{Figure 2}

In order to compare the antioxidant properties of the methanol and $\beta$-CD solution extracts obtained by UAE with the 1:50 plant/solvent ratio, their radical scavenging activities were investigated through reaction with DPPH $\bullet\left(\mathrm{Hsu}, \mathrm{Chan} \&\right.$ Chang, 2007) and the ORAC $\mathrm{FL}_{\mathrm{FL}}$ assay (Ninfali, Gennari, Biagiotti, Cangi, Mattoli \& Maidecchi, 2009). The same assays were performed on the reference compound resveratrol (Lee, Seo, Lee, Chung \& Chi, 2004; Ninfali 2009). The $\beta$-CD extract was reextracted with methanol prior to use to obtain free- $\beta-C D$ extract.

$\mathrm{DPPH} \bullet$ is a stable radical which has been widely accepted as a tool for estimating the free radicalscavenging activities of herbal extracts. The results which are expressed as $\mathrm{EC}_{50}(\mu \mathrm{g} / \mathrm{ml})$ and refer to the extract concentration needed to scavenge $50 \%$ of the initial DPPH• concentration after $30 \mathrm{~min}$ incubation, are reported in Table 2. Analysis of the values shows that both extracts obtained via the UAE of Polygonum c. behave as good radical scavengers regardless of the extracting solvent, with $\mathrm{EC}_{50} \mathrm{~s}$ comparable to that of reference compound resveratrol, a result which highlights the antioxidant properties of both extracts. 


\section{Table 2}

In Figure 3a we report the time-dependent decrease in DPPH absorbance at $517 \mathrm{~nm}$ in the presence of similar concentrations of either $\mathrm{MeOH}$ extract, or $\beta-\mathrm{CD}$ extract of $P$. cuspidatum, or resveratrol: the equilibria between DPPH and scavengers are reached in different times.

\section{Figure 3}

More significant results in terms of antioxidant capacity are provided by the ORAC $\mathrm{FL}_{\mathrm{F}}$ test which is based on the inhibition of the peroxyl radical-induced oxidation of fluorescein initiated by the thermal decomposition of 2,2'-azobis(2-amidinopropane)dihydrochloride (AAPH). The ORAC $\mathrm{FL}$ test is the only method that combines the evaluation of both the degree of inhibition and the inhibition time in a single quantity (ORAC value). The ORAC value has been widely used for the standardization of herbal extract and food antioxidant activity. The ORAC values obtained for the two extracts and for resveratrol are reported in Table 2, the resveratrol value is comparable with data reported in literature. Fluorescence decay curves induced by AAPH in the presence of different concentrations of either the sonicated $\beta-\mathrm{CD}$ extract or of the reference compound resveratrol are reported in Fig. 3b. Again the ORAC value obtained for methanol and $\beta-C D$ extracts are comparable, a result which confirms the UAE with $\beta-C D$ method as an excellent alternative to organic solvent extraction of the pool of antioxidants from $P$. cuspidatum.

\section{Conclusion}

A new extraction method, which avoids the use of organic solvents, was efficiently applied to the extraction of resveratrol and polydatin from the roots of $P$. cuspidatum. The extract obtained with a $\beta$-cyclodextrin water solution maintains the same radical scavenging activity and antioxidant capacity as the methanol extract obtained under the same conditions (sonication, plant/solvent ratio, elimination of extraction solvent prior to antioxidant tests). Moreover $\beta-\mathrm{CD}$, if present in the final extract, could be a useful tool in improving the solubility, stability and bioavailability of resveratrol as an ingredient in foods. In conclusion, the combination of UAE and the capability of cyclodextrins to form inclusion complexes allow the use of water as the extraction media. The freeze dried or spray dried extract powder is an excellent active component for food supplements or phytochemical preparations.

\section{Acknowledgements}

We are grateful to Regione Piemonte (Projects Nutrapiem 2009) and MIUR (PRIN 2008) for financial support and to MB Med (Rivalta, Torino) for providing the plant material.

\section{References}

Benova, B., Adam, M., Pavlikova, P., Fischer, J. (2010). Supercritical fluid extraction of piceid, resveratrol and emodin from Japanese Knotweed. The Journal of Supercritical Fluids, 51, 325-330. 
Bertelli, A. A., Ferrara, F., Diana, G., Fulgenzi, A., Corsi, M., Ponti, W., Ferrero, M. E., Bertelli, A. (1999). Resveratrol, a natural stilbene in grapes and wine, enhances intraphagocytosis in human promonocytes: a co-factor in antiinflammatory and anticancer chemopreventive activity. International Journal of Tissue Reactions, 21, 93-104.

Bondet, V., Brand-Williams, W., Berset, C. (1997). Kinetics and mechanisms of antioxidant activity using the DPPH·free radical method, Lebensm.-Wiss. Technol. 30, 609-615.

Casazza, A., Aliakbarian, B., Mantegna, S., Cravotto, G., Perego, P. (2010). Extraction of phenolics from Vitis vinifera wastes under non-conventional techniques. Journal of Food Engineering, 100, $50-55$.

Chemat, F., Zill-e-Huma, Khan, M. K. (2011). Applications of ultrasound in food technology: Processing, preservation and extraction, Ultrasonics Sonochemistry 18, 813-835.

Chukwumah, Y. C., Walker, L. T., Verghese, M., Ogutu, S. (2009). Effect of frequency and duration of ultrasonication on the extraction efficiency of selected isoflavones and trans-resveratrol from peanuts (Arachis hypogaea). Ultrasonics Sonochemistry, 16, 293-299.

Cravotto, G., Binello, A., Baranelli, E., Carraro, P., Trotta, F. (2006). Cyclodextrins as food additives and in food processing. Current Nutrition \& Food Science, 2, 343-350.

Cravotto, G., Cintas P. (2007). Extraction of flavourings from natural sources; in Modifying flavour in food. Edited by A J Taylor and J Hort, (Chapter 3), pp 41-63. Woodhead Publishing Limited, Cambridge, CB1 6AH, England, ISBN 1845690745.

Fan, P., Marston, A., Hay, A. E., Hostettmann, K. (2009). Rapid separation of three glucosylated resveratrol analogues from the invasive plant Polygonum cuspidatum by high-speed counter-current chromatography. Journal of Separation Science, 32, 2979-2984.

Hsu, C-Y., Chan, Y-P., Chang J. (2007). Antioxidant activity of extract from Polygonum cuspidatum. Biological Research, 40, 13-21.

Lee, H.J., Seo, J.W., Lee, B.H.., Chung, K.H., Chi, D.Y. (2004). Syntheses and radical scavenging activities of resveratrol derivatives. Bioorganic \& Medicinal Chemistry Letters, 14, 463-466.

Li, M. H., Chen, J. K., Huang S. S., Lee, R. S., Su, M. J. (2000). Cardioprotective effect of resveratrol, a natural antioxidant derived from grapes. Cardiovascular Research, 47, 549-555.

Li, H., Li, G. K., Zhang, Z. X. (2003). Effects of operating parameters on the extraction of resveratrol in Huzhang (Polygonum cuspidatum) using microwave-assisted extraction. Chinese Journal of Analytical Chemistry, 31, 1341-1344.

Liu, D., Tang, H. F., Zhang, S. Q., Bi, L. L., Wang, J. W., Zhao, Y. P. (2007). The optimization of extraction process for effective ingredients in Poligonum cuspidatum (in Chinese). Chinese Traditional Patent Medicine, 29, 516-521.

Lopez-Nicolas, J. M., Rodriguez-Bonilla, P., Garcia-Carmona, F. (2009). Complexation of pinosylvin, an analogue of resveratrol with high antifungal and antimicrobial activity, by different types of cyclodextrins. Journal of Agricultural and Food Chemistry, 57, 10175-10180. 
Lu, Z., Chen, R., Liu, H., Hu, Y., Cheng, B., Zou, G. (2008). Study of the complexation of resveratrol with cyclodextrins by spectroscopy and molecular modeling. Journal of Inclusion Phenomena and Macrocyclic Chemistry, 63, 295-300.

Lu, Z., Cheng, B., Hu, Y., Zhang, Y., Zou, G. (2009). Complexation of resveratrol with cyclodextrins: solubility and antioxidant activity. Food Chemistry, 113, 17-20.

Lucas-Abellán, C., Fortea, I., López-Nicolás, J. M., Núñez-Delicado, E. (2007). Cyclodextrins as resveratrol carrier system. Food Chemistry, 104, 39-44.

Mason, T., Chemat, F., Vinatoru, M . (2011). The extraction of natural products using ultrasound and microwaves, Current Organic Chemistry, 15, 237-247.

Ninfali, P., Gennari, L., Biagiotti, E., Cangi, F., Mattoli, L., Maidecchi, A. (2009). Improvement in Botanical Standardization of commercial Freeze-dried herbal extracts by using the Combination of antioxidant capacity and costituent marker concentrations. Journal of AOAC International, 92, 797805.

Okuda, T., Yokotsuka, K. (1996). Trans-resveratrol concentrations in berry skins and wines from grapes grown in Japan. American Journal of Enology and Viticulture, 47, 93-99.

Ou, B., Hampsch-Woodill, M., Prior, R. L. (2001). Development and validation of an improved oxygen radical absorbance capacity assay using fluorescein as the fluorescent probe. Journal of Agricultural and Food Chemistry, 49, 4619-4626.

Pezet, R., Perret, C., Jean-Denis, J. B., Tabacchi, R., Gindro, K., Viret, O. (2003). Delta-viniferin, a resveratrol dehydrodimer: one of the major stilbenes synthesized by stressed grapevine leaves Journal of Agricultural and Food Chemistry, 51, 5488-5492.

Qian, G. S., Leung, S. Y., Lu, G. H., Leung, K. S. Y. (2008). Optimization and validation of a chromatographic method for the simultaneous quantification of six bioactive compounds in Rhizoma et Radix Polygoni Cuspidati. Journal of Pharmacy and Pharmacology, 60 (1), 107-113.

Sun, D., Zhang, Z. X. Chinese Patent 1,116,264C (July 30, 2003).

Szente, L., Szejtli, J. (2004). Cyclodextrins as food ingredients. Trends in Food Science \& Technology, 15, 137-142.

Vastano, B. C., Chen, Y., Zhu, N., Ho, C., Zhou, Z., Rosen, R. T. (2000). Isolation and identification of stilbenes in two varietes of Poligonum cuspidatum. Journal of Agricultural and Food Chemistry, 48, 253-256.

Wang, H., Dong, Y., Xiu, Z. (2008). Microwave-assisted aqueous two-phase extraction of piceid, resveratrol and emodin from Poligonum cuspidatum by ethanol/ammonium sulphate systems. Biotechnology Letters, 30, 2079-2084.

Xiang, H. Y., Zhou, C. S., Lei, Q. F., Chen, L. S. (2005). Studies on separation and purification of piceid from Poligonum cuspidatum by macroporus adsorption resin (in Chinese). Chinese Pharmaceutical Journal, 40, 96-98.

Yu, W., Shu, B., Zhao, Y. (2005). Supercritical $\mathrm{CO}_{2}$ extraction of resveratrol and its glycoside piceid from Chinese traditional medicinal herb Polygonum cuspidatum. Journal of the Science of Food and Agriculture, 85, 849-492. 
Zhang, D., Li, X., Hao, D., Li, G., Xu, B., Ma, G., Su, Z. (2009). Systematic purification of polydatin, resveratrol and anthraglycoside B from Polygonum cuspidatum Sieb. et Zucc. Separation and Purification Technology, 66, 329-339.

Zhuang, X., Dong, X., Ma, S., Zhang, T. (2008). Selective on-line extraction of trans-resveratrol and emodin from Polygonum cuspidatum using molecularly imprinted polymer. Journal of Chromatographic Science, 46, 739-742. 


\section{Figures Captions}

Figure 1. HPLC chromatograms of UAE: $\beta$-CD sol. extract (a) and methanol extract (b).

Figure 2. From left $\beta-C D$ and $H P \beta-C D$ extracts.

Figure 3. a) Decrease in DPPH absorbance in the absence or in the presence of either the $\beta-C D$ extract, or $\mathrm{MeOH}$ extract or resveratrol; b) relative fluorescence decay curves of fluorescein in the absence and in the presence of different concentrations of $\beta-C D$ extract or resveratrol. 
Table 1. Extraction conditions and yields (average of triplicate experiments).

\begin{tabular}{|c|c|c|c|c|c|}
\hline $\begin{array}{l}\text { Solvent } \\
(\mathrm{ml} / \mathrm{g} *)\end{array}$ & Method & $\begin{array}{c}\text { Resveratrol } \\
\text { "free" } \\
(\mathrm{mg} / \mathrm{g} *)\end{array}$ & $\begin{array}{c}\text { Polydatin } \\
(\mathrm{mg} / \mathrm{g} *)\end{array}$ & $\begin{array}{c}\text { Resveratrol } \\
\text { “cleaved } \\
\text { glucoside" } \\
(\mathrm{mg} / \mathrm{g} *)\end{array}$ & $\begin{array}{c}\text { Resveratrol } \\
\text { "total" } \\
\left(\mathrm{mg} / \mathrm{g}^{*}\right)\end{array}$ \\
\hline Methanol (50 ml/g) & $\mathrm{UAE}^{\#}$ & 2.15 & 11.84 & 6.92 & 9.07 \\
\hline$\beta$-CD sol. $(50 \mathrm{ml} / \mathrm{g})$ & $\mathrm{UAE}^{\#}$ & 2.35 & 9.64 & 5.62 & 7.51 \\
\hline Methanol (50 ml/g) & stirring & 1.89 & 9.62 & 5.64 & 7.99 \\
\hline$\beta-\mathrm{CD}$ sol. $(50 \mathrm{ml} / \mathrm{g})$ & stirring & 1.48 & 6.49 & 3.79 & 5.27 \\
\hline$\beta$-CD sol. $(25 \mathrm{ml} / \mathrm{g})$ & $\mathrm{UAE}^{\#}$ & 1.78 & 7.51 & 4.39 & 6.17 \\
\hline HP $\beta-C D$ sol. $(25 \mathrm{ml} / \mathrm{g})$ & $\mathrm{UAE}^{\#}$ & 1.10 & 4.98 & 2.91 & 4.01 \\
\hline Water $(50 \mathrm{ml} / \mathrm{g})$ & $\mathrm{UAE}^{\#}$ & 0.019 & - & - & 0.019 \\
\hline
\end{tabular}

Table 2: $\mathrm{DPPH} \mathrm{EC}_{50}$ values and $\mathrm{ORAC}_{\mathrm{FL}}$ values for the two extracts obtained by UAE with methanol and $\beta$-CD solution with the 1:50 plant/solvent ratio and for resveratrol taken as reference compound.

\begin{tabular}{|c|c|c|}
\hline & $\begin{array}{c}\text { DPPH EC E0 }(\mu \mathrm{g} / \mathrm{ml})(\text { C.L. } \\
95 \%)\end{array}$ & ORAC FL \pm S.E.M. \\
\hline$\beta-\mathrm{CD}$ extract & $18.4(15.2-11.3)$ & $\begin{array}{c}9106 \pm 909 \\
(\mu \mathrm{mol} \text { TE/ g dry extract })\end{array}$ \\
\hline $\mathrm{MeOH}$ extract & $8.3(8.9-7.7)$ & $\begin{array}{c}7749 \pm 617 \\
(\mu \mathrm{mol} \text { TE/ g dry extract })\end{array}$ \\
\hline resveratrol & $13.1(11.3-15.2)$ & $\begin{array}{c}49642 \pm 4315 \\
(\mu \mathrm{mol} \text { TE/ g resveratrol })\end{array}$ \\
\hline
\end{tabular}



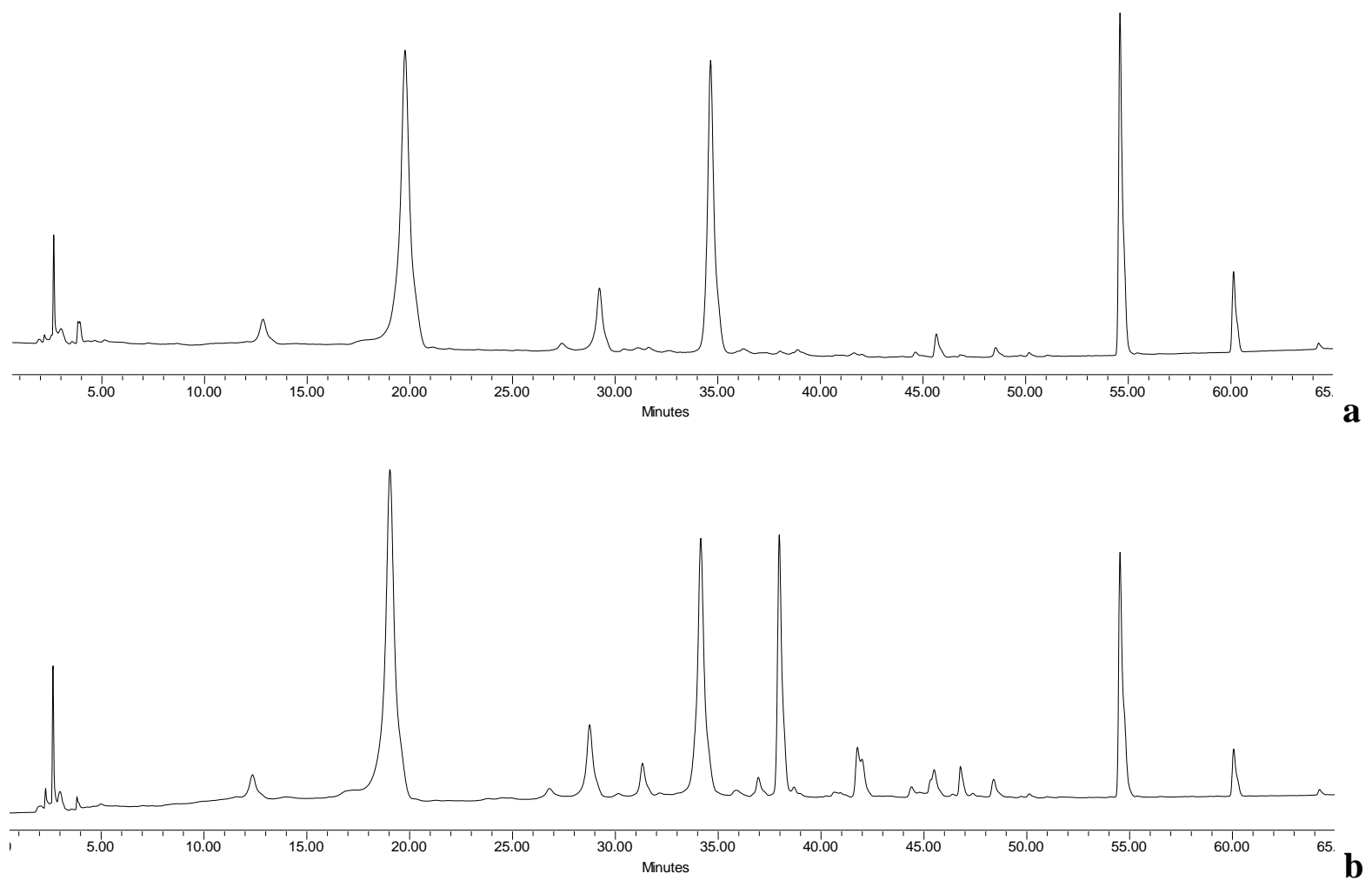

Figure 1. 
Figure 2 


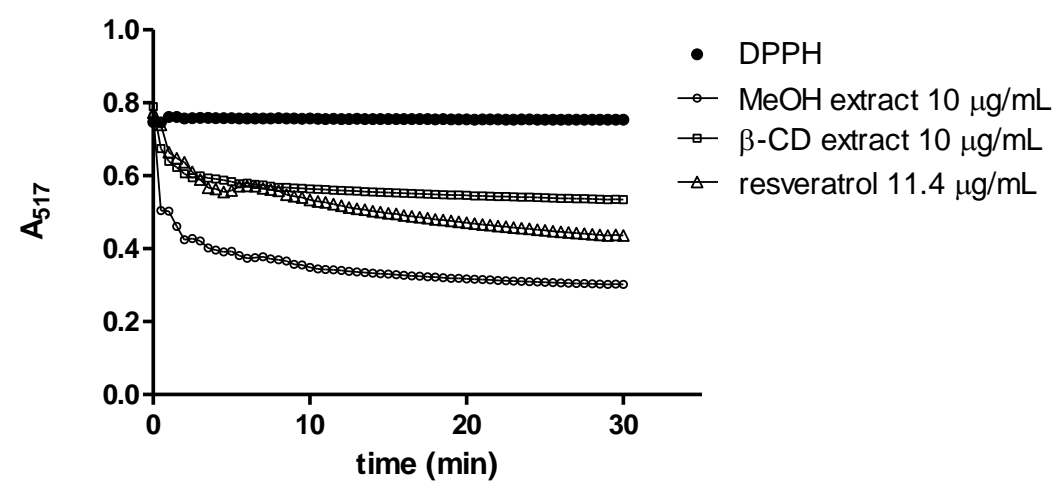

3b

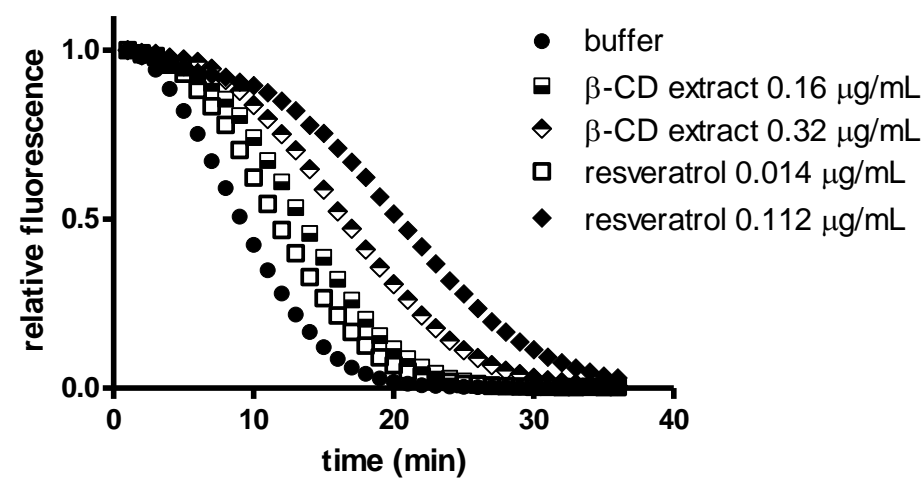

Figure 3 